\title{
Morfologia e fitomassa do girassol cultivado com déficits hidricos em diferentes estádios de desenvolvimento ${ }^{1}$
}

\author{
Alexandre R. A. da Silva ${ }^{2}$, Francisco M. L. Bezerra ${ }^{2}$, Cley A. S. de Freitas ${ }^{3}$, \\ João V. Pereira Filho ${ }^{2}$, Ricardo R. de Andrade $^{2} \&$ Daniel R. C. Feitosa ${ }^{4}$
}

\begin{abstract}
RESUMO
Objetivou-se, com este trabalho, avaliar a morfologia, a produção e a partição de fitomassa do girassol cv. Multissol quando submetido a déficits de irrigação em Pentecoste, CE. Utilizou-se o delineamento estatístico em blocos ao acaso, em esquema de parcelas subdivididas no tempo $(8 \times 3)$, com quatro repetições, sendo os tratamentos definidos em função da época de indução do déficit de irrigação nos estádios vegetativo, floração e formação da produção, correspondendo à ocorrência de déficit hídrico em 1, 2 ou 3 estádios e três épocas de avaliação (aos 52, 68 e $110^{\circ}$ dia após a semeadura). A altura da planta, o número de folhas e o diâmetro do caule foram negativamente afetados pelos efeitos isolados dos déficits de irrigação e das épocas de avaliação. Os déficits de irrigação e as épocas de avaliação interagiram e afetaram a área foliar, a massa seca da folha, do pecíolo, do caule, do capítulo e total. A melhor resposta em ganhos de crescimento e de produção de fitomassa deu-se no tratamento sem déficit de irrigação, em todo o ciclo. Os déficits de irrigação não modificaram a partição de fitomassa. O nível de irrigação equivalente a $50 \%$ da ETo comprometeu a morfologia e a produção de fitomassa quando aplicado em qualquer estádio de desenvolvimento.
\end{abstract}

Palavras-chave: Helianthus annuus L., estresse hídrico, análise de crescimento

\section{Morphology and biomass of sunflower plants grown under water deficits in different development stages}

ABSTRACT

The objective of the present study was to evaluate the morphology, biomass production and biomass partition of sunflower (Multissol cultivar) when subjected to water deficit at Pentecoste, CE - Brazil. An experimental design in randomized blocks was used as split plots in time $(8 \times 3)$ with four replications, with the treatments defined by the development stage for application of water deficit vegetative, flowering and formation of production stages corresponding to the occurrence of water deficit at stages 1,2 or 3 and three evaluation periods at 52,68 and 110 days after sowing. The plant height, number of leaves and stem diameter were negatively influenced by the isolated effects of the water deficits and evaluation periods. The water deficits and evaluation periods interacted and affected the leaf area, dry mass of leaves, petiole, stem, head and total. The best response in terms of growth and biomass production occurred in the treatment presenting no water deficit throughout the cycle. The irrigation deficits did not change the biomass partition. The irrigation level equivalent to $50 \%$ of the ETo compromised morphology and biomass production, when applied at any development stage.

Key words: Helianthus annuus L., water stress, growth analysis

\footnotetext{
${ }^{1}$ Extraído da Dissertação de Mestrado apresentada pelo primeiro autor ao Programa de Pós-Graduação em Engenharia Agrícola da Universidade Federal do Ceará (UFC), Fortaleza, CE

${ }^{2}$ DEA/UFC. Campus do Pici, Bloco 804, CEP 60455-760, Fortaleza, CE. E-mail: alexandre_reuber@hotmail.com; mbezerra@ufc.br; joao valdenor@hotmail.com; rr-andrade@hotmail.com

3 Instituto Federal de Educação, Ciência e Tecnologia do Ceará, Campus Avançado de Tianguá, CEP 60115-282, Tianguá, CE. E-mail: anderson_agrotec@yahoo.com.br

${ }^{4}$ FEAGRI/ŪNICAMP, CEP 13083-970, Campinas, SP. E-mail: daniel.feitosa@yahoo.com.br
} 


\section{INTRODUÇÃO}

Originário da América do Norte, o girassol, Helianthus annus L., é uma dicotiledônea anual adaptada às mais diversas condições edafoclimáticas, cultivada em todos os continentes (Fagundes et al., 2007).

Além da produção de grãos, o girassol vem sendo largamente cultivado objetivando o fornecimento de matéria-prima para a indústria alimentícia e se destaca como uma das oleaginosas potencialmente promissora, capaz de fomentar o programa Biodiesel no Brasil (Santos Júnior et al., 2011).

Entre as demais aplicações da cultura menciona-se sua utilização como forrageira alternativa (Oliveira et al., 2003). Daí, a importância de se avaliar características agronômicas e morfológicas relevantes à utilização da espécie para tal fim (Tomich et al., 2003). A este respeito, Mizubuti et al. (2002) compararam, qualitativamente, as silagens de milho, sorgo e girassol e evidenciaram que, bromatologicamente, as silagens de milho e girassol se assemelharam e se caracterizaram por possuir uma qualidade superior quando equiparadas ao sorgo.

Dentre os recursos utilizados pelas plantas considera-se que a água é o mais requerido e, ao mesmo tempo, o mais frequentemente limitante. Considera-se, desta forma, que a necessidade de se recorrer à prática da irrigação reflete o fato de que a água é essencial para a produtividade dos vegetais, cujo desenvolvimento é afetado de maneira bastante significativa devido à disponibilidade hídrica, tanto pela sua falta ou excesso (Taiz \& Zeiger, 2009).

A deficiência hídrica exerce influências negativas sobre as plantas e, na maioria dos casos, seus danos são mensurados mediante o acompanhamento dos processos que, em geral, estão relacionados ao crescimento, como as alterações que ocorrem a nível morfológico e no acúmulo de biomassa, por parte dos distintos órgãos vegetais (Carvalho, 2004). Neste contexto, a análise de crescimento, além de descrever as condições morfofisiológicas dos vegetais possibilita a avaliação do seu desenvolvimento, como um todo, e a contribuição relativa dos diferentes órgãos no crescimento total. A partir dos dados de crescimento pode-se deduzir, ainda, inferências acerca das eventuais causas de alterações nos padrões de crescimento entre as plantas cultivadas sob diferentes condições de manejo.

Os vegetais de cultivo anual em crescimento apresentam, ao longo de seus ciclos, diferentes estádios fenológicos, caracterizados por alterações que ocorrem na forma do organismo ou nos órgãos em que cada qual possui uma exigência diferenciada de água, visto que diferentes processos fisiológicos são prevalecentes nos diversos estádios de desenvolvimento das plantas e que alguns desses são mais sensíveis que outros à redução do potencial da água nos solos e, por conseguinte, nos tecidos vegetais (Grieu et al., 2008).

Assim, o conhecimento apenas da necessidade total d'água consumida pela cultura ao longo do ciclo não se traduz em um hábil manejo da irrigação, razão pela qual Fereres \& Soriano (2007) propuseram o conceito de irrigação deficitária, que consiste na aplicação de lâminas de água inferiores às estimadas pelas metodologias que, tradicionalmente, determinam os requerimentos hídricos, ao longo dos distintos estádios fenológicos.
O conhecimento do desempenho das espécies vegetais diante da aplicação do manejo da irrigação com déficit regulado pode ser de grande valia quando se almeja uma ampliação na produtividade da água e pode explicar a capacidade de tolerância e/ou sensibilidade à deficiência hídrica das culturas quando imposta ao longo de seus diferentes estádios fenológicos, tendo em vista que os efeitos dos déficits hídricos variam com os estádios em que os mesmos se manifestam e cujas respostas podem até apontar efeitos maléficos do déficit sob o crescimento, embora possam resultar em um equilíbrio funcional entre a água empregada e a fitomassa produzida (Toureiro et al., 2007).

Castro et al. (2006) estudaram a influência do estresse hídrico na produção de matéria seca total do girassol e observaram que as maiores produções foram obtidas nos tratamentos em que se aplicou uma quantidade maior de água.

Segundo Leite et al. (2005), quando a deficiência hídrica incide nos estádios iniciais da estação de cultivo do girassol a planta manifesta, a nível celular, perdas no turgor e, em consequência, redução do crescimento afetando, sobremaneira, a morfologia de órgãos como raízes, folhas, pecíolos, caules e capítulos.

Toureiro et al. (2007) relatam que dentre os mecanismos fisiológicos adaptativos desenvolvidos pela cultura do girassol perante o déficit hídrico se destaca a aceleração do processo de senescência das folhas que, desta forma, objetiva restringir a área foliar e, em contrapartida, a superfície exposta às perdas, por transpiração.

Em função dessas considerações é possível que o déficit hídrico imposto em diferentes estádios de desenvolvimento da cultura do girassol interfira na sua morfologia, na produção de fitomassa seca total e promova partições diferenciadas de fotoassimilados entre os órgãos aéreos das plantas.

Objetivou-se então, com este trabalho, avaliar os efeitos de déficits de irrigação aplicados nos diferentes estádios do desenvolvimento do girassol sobre a morfologia, a produção de fitomassa seca dos constituintes da parte aérea (caule, folha, pecíolo e capítulo) e a participação de cada um deles em relação à produção de fitomassa seca total (partição).

\section{Material E MÉTODOS}

O experimento foi desenvolvido na Fazenda Experimental Vale do Curu (FEVC), que pertence à Universidade Federal do Ceará (UFC), em Pentecoste, CE, sendo conduzido de setembro a dezembro de 2010. As coordenadas geográficas locais de referência são latitude $3^{\circ} 49^{\prime} 25^{\prime \prime} \mathrm{S}$, longitude $39^{\circ} 20^{\prime} 20^{\prime \prime} \mathrm{W}$ e altitude média de $50 \mathrm{~m}$.

Segundo Köeppen, o clima é do tipo BSw'h', semiárido, seco, existindo uma pequena temporada úmida. As médias históricas dos dados meteorológicos do município de Pentecoste, CE, no período compreendido entre os anos de 1970 a 2000, indicam pluviosidade media anual de 800,9 mm; temperatura média de $26,6^{\circ} \mathrm{C}$; umidade relativa do ar média de $75 \%$; nebulosidade média de 5,1 n-10; total de insolação de 2.799,6 h e total de evaporação de Piche de 1.552,4 mm. 
Tabela 1. Caracterização química e textural do solo nas camadas $0-0,20$ e $0,20-0,40 \mathrm{~m}^{1}$

\begin{tabular}{|c|c|c|c|c|c|c|c|c|c|c|c|}
\hline \multirow{2}{*}{ Camada (m) } & \multirow{2}{*}{$\mathrm{pH}$} & $\mathbf{P}$ & $\mathrm{K}$ & $\mathrm{Na}$ & $\mathrm{Mg}$ & Al & $\mathrm{Ca}$ & M.0 & Argila & Silte & Areia \\
\hline & & \multicolumn{3}{|c|}{$\left(\mathrm{mg} \mathrm{dm}^{-3}\right)$} & \multicolumn{3}{|c|}{$\left(\mathrm{cmol}_{\mathrm{c}} \mathrm{dm}^{-3}\right)$} & \multicolumn{4}{|c|}{$\left(\mathrm{g} \mathrm{kg}^{-1}\right)$} \\
\hline $0-0,20$ & 7,20 & 78,00 & 515,00 & 73,00 & 3,70 & 0,00 & 4,80 & 18,93 & 83 & 224 & 693 \\
\hline $0,20-0,40$ & 7,20 & 56,00 & 246,00 & 70,00 & 4,00 & 0,00 & 4,50 & 12,00 & 90 & 231 & 679 \\
\hline
\end{tabular}

${ }^{1}$ Análises realizadas no Laboratório de Solos e Água, do Departamento de Ciências do Solo do CCA/UFC

O solo em que foi instalado o experimento é da classe dos Neossolos flúvicos, textura franco-arenosa, cujas análises químicas e textural nas camadas de $0-0,20 ; 0,20-0,40 \mathrm{~m}$ se encontram na Tabela 1.

O preparo do solo constou de uma aração seguida de duas gradagens cruzadas. A adubação foi baseada na análise de solo e nas exigências nutricionais da cultura, conforme Aquino et al. (1993). As quantidades recomendadas foram: 60-30-30 $\mathrm{kg} \mathrm{ha}^{-1}$ de NPK (nitrogênio, fósforo e potássio). Como fonte de N utilizou-se a uréia, de P o fosfato monoamônio (MAP) e de K o sulfato de potássio. A adubação de fundação foi realizada nos sulcos e a adubação de cobertura foi parcelada e aplicada via água de irrigação, conforme a taxa de absorção de nutrientes da cultura adaptada a partir de Leite et al. (2005) apresentada na Tabela 2. Foram aplicados, também, em solos, todos os tratamentos $10 \mathrm{~kg} \mathrm{ha}^{-1}$ de micronutrientes na forma comercial do fertilizante mineral FTE BR-12 (9\% Zn; 1,8\% B; 0,85\% Cu; $3 \%$ Fe; $2,1 \%$ Mn; e $0,10 \%$ Mo) e $4 \mathrm{~kg} \mathrm{ha}^{-1}$ de boro (B) utilizandose, como fonte, o ácido bórico.

Tabela 2. Valores percentuais (\%) de nitrogênio $(N)$, fósforo $(\mathrm{P})$, potássio $(\mathrm{K})$ e boro $(\mathrm{B})$ aplicados na semeadura e ao longo das fertirrigações, durante o desenvolvimento da cultura do girassol*

\begin{tabular}{crrrr}
\hline \multirow{2}{*}{ DAS } & \multicolumn{1}{c}{$\mathbf{N}$} & $\mathbf{P}$ & $\mathbf{K}$ & \multicolumn{1}{c}{$\mathbf{B}$} \\
\cline { 2 - 5 } & \multicolumn{4}{c}{$\mathbf{( \% )}$} \\
Semeadura & 11,58 & 6,25 & 7,45 & 0,00 \\
$28^{\circ}$ & 18,95 & 21,88 & 21,58 & 17,47 \\
$35^{\circ}$ & 18,95 & 21,88 & 21,58 & 17,47 \\
$42^{\circ}$ & 12,11 & 18,75 & 18,32 & 21,08 \\
$49^{\circ}$ & 12,11 & 18,75 & 18,32 & 21,08 \\
$56^{\circ}$ & 5,26 & 6,25 & 3,88 & 6,33 \\
$63^{\circ}$ & 5,26 & 6,25 & 3,88 & 6,33 \\
$70^{\circ}$ & 7,89 & 0,00 & 2,48 & 5,12 \\
$77^{\circ}$ & 7,89 & 0,00 & 2,48 & 5,12 \\
\hline Total & 100 & 100 & 100 & 100 \\
\hline
\end{tabular}

Adaptado de Leite et al. (2005); DAS - Dia após a semeadura

A cultura do girassol, cultivar Multissol, foi implantada no experimento com espaçamento entre as fileiras de plantas de 0,9 e $0,25 \mathrm{~m}$ entre as plantas nas fileiras.

O desenvolvimento da cultura foi dividido em três estádios fenológicos, conforme a seguir: (a) estádio vegetativo: da semeadura até o estádio inicial de floração; (b) estádio de floração: estendeu-se do final do estádio anterior até a fase de floração final; (c) estádio de formação da produção: do final do estádio anterior até a colheita.

O delineamento experimental utilizado foi o de blocos casualizados, em esquema de parcelas subdivididas no tempo, com oito parcelas, 3 subparcelas e quatro repetições.

Nas parcelas, com área de $16,2 \mathrm{~m}^{2}(2,7 \times 6 \mathrm{~m})$, foram avaliados os tratamentos, que foram definidos em função da época de indução do déficit hídrico nos diferentes estádios fenológicos da cultura e, nas subparcelas, as épocas de avaliação (52, 68 e $110^{\circ}$ dia após a semeadura - DAS). A área total ocupada pelo experimento foi de $864 \mathrm{~m}^{2}$ (28,8 x $\left.30 \mathrm{~m}\right)$, composta de 128 linhas de plantio; cada linha útil de plantas ocupou uma área de 5,4 m² e continha 24 plantas cada uma.

Os tratamentos alocados nas parcelas corresponderam à ocorrência de déficit hídrico em um, dois ou três estádios e foram assim agrupados: T1 - tratamento em que a cultura não sofreu nenhum déficit hídrico nos três estádios fenológicos; T2 - a cultura sofreu déficit hídrico no estádio de formação da produção; T3 - déficit hídrico no estádio de floração; T4 - déficit hídrico nos estádios de floração e formação da produção; T5 déficit hídrico no estádio vegetativo; T6 - déficit hídrico nos estádios vegetativo e formação da produção; T7 - déficit hídrico nos estádios vegetativo e floração e T8: déficit hídrico nos três estádios fenológicos.

O experimento foi irrigado pelo método localizado, com o sistema do tipo gotejamento sobre linha. Após a semeadura a área experimental foi irrigada diariamente com uma lâmina equivalente a $100 \%$ da evapotranspiração de referência (ETo) estimada através da evaporação medida em um tanque Classe A, a fim de garantir a uniformidade do estande até o início da diferenciação dos tratamentos, que se deu no $21^{\circ}$ dia após a semeadura (DAS). Após a diferenciação dos tratamentos a quantidade de água aplicada passou a ser reposta a cada dois dias e as lâminas aplicadas continuaram tendo, por base, a ETo. As unidades experimentais submetidas ao déficit hídrico ao longo do ciclo da cultura receberam $50 \%$ da lâmina de água aplicada no Tratamento 1.

Durante o período de condução do experimento procederamse aos tratos culturais e controle fitossanitário, sempre que necessário, seguindo-se as recomendações sugeridas por Leite et al. (2005).

As variáveis morfológicas (número de folhas, altura de plantas, diâmetro do caule e área foliar) foram avaliadas amostrando-se dez plantas inseridas na área útil do experimento.

A área foliar foi estimada com base na dimensão de largura máxima de todas as folhas vivas, adotando-se o modelo proposto por Maldaner et al. (2009), conforme a Eq. 1, apresentada a seguir:

$$
\mathrm{AF}=1,7582 \mathrm{~L}^{1,7067}
$$

em que:

$\mathrm{AF}$ - área foliar da folha, $\mathrm{cm}^{2}$

L - largura máxima da folha, $\mathrm{cm}$

Obteve-se o número de folhas totalmente abertas por planta por meio da contagem direta das folhas. Com o auxílio de uma trena métrica graduada em centímetros foi mensurada a altura 
das plantas e o diâmetro do caule foi mensurado a uma altura de aproximadamente $5 \mathrm{~cm}$ da superfície do solo com o auxílio de paquímetro digital.

Visando às avaliações de produção e à partição de fitomassa coletaram-se, de forma aleatória, quatro plantas de cada tratamento, em cada bloco; após a coleta as plantas foram separadas em: parte vegetativa (caules, folhas e pecíolos) e em parte reprodutiva (capítulos); em seguida, foram pesadas para quantificação da massa fresca enquanto as amostras foram acondicionadas em sacos de papel e colocadas para secar em estufa com circulação de ar forçado mantendo-se a temperatura na faixa de 65 a $70{ }^{\circ} \mathrm{C}$, até a manutenção de peso constante; prosseguindo-se, após a secagem cada amostra foi pesada em balança de precisão e só então foi possível determinar a participação percentual de cada constituinte quanto à produção de fitomassa total.

Os dados foram submetidos à análise da variância pelo teste F a 0,01 de probabilidade. Quando verificado efeito significativo, as médias obtidas nos tratamentos foram comparadas pelo teste de Tukey ( $\mathrm{p} \leq 0,05)$; nessas análises foi utilizado o software estatístico Assistat versão 7.6 beta.

\section{RESULTADOS E DISCUSSÃO}

O resumo das análises das variâncias para os dados morfológicos de altura de plantas $\left(\mathrm{A}_{\mathrm{P}}\right)$, número de folhas $\left(\mathrm{N}_{\mathrm{F}}^{\mathrm{o}}\right)$, diâmetro do caule $\left(\Phi_{\mathrm{C}}\right)$, área foliar $\left(\mathrm{A}_{\mathrm{F}}\right)$ e de fitomassa, matéria seca da folha $\left(\mathrm{MS}_{\mathrm{F}}\right)$, do pecíolo $\left(\mathrm{MS}_{\mathrm{P}}\right)$ do caule $\left(\mathrm{MS}_{\mathrm{CAU}}\right)$, do capítulo $\left(\mathrm{MS}_{\mathrm{CAP}}\right)$ e total $\left(\mathrm{MS}_{\mathrm{T}}\right)$ do girassol pode ser observado na Tabela 3.

Verificou-se, de acordo com os resultados, que os efeitos principais dos tratamentos e das épocas de avaliação variaram independentemente e influenciaram, em nível de 0,01 de probabilidade pelo teste $\mathrm{F}$, as características morfológicas $\mathrm{A}_{\mathrm{p}}$, $\mathrm{N}_{\mathrm{F}}^{\mathrm{o}}$ e $\Phi_{\mathrm{C}}$ e nenhuma das interaçõos foi significativa (Tabela 3). Com relação à $A_{F}$ verificou-se efeito significativo para tratamentos $(\mathrm{T})$, épocas de avaliação $(\mathrm{E})$, tal como para a

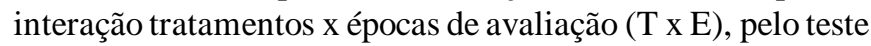
$\mathrm{F}(\mathrm{p} \leq 0,01)$, conforme Tabela 3 .

Em relação às variáveis relacionadas à fitomassa $\mathrm{MS}_{\mathrm{F}}, \mathrm{MS}_{\mathrm{P}}$ $\mathrm{MS}_{\mathrm{CAU}}, \mathrm{MS}_{\mathrm{CAP}}$ e $\mathrm{MS}_{\mathrm{T}}$, observa-se, na Tabela 3, que as mesmas foram influenciadas significativamente pelos fatores tratamento (T) e épocas de avaliação (E), e para a interação tratamentos $\mathrm{X}$ épocas de avaliação ( $\mathrm{T} \times \mathrm{E})$, pelo teste $\mathrm{F}(\mathrm{p} \leq 0,01)$, indicando dependência entre os fatores da interação de tal forma que existem diferenças entre os tratamentos quando aplicados em cada época distinta de desenvolvimento da cultura.

Os valores médios de $\mathrm{A}_{\mathrm{P}}, \mathrm{N}_{\mathrm{F}}^{\mathrm{o}}$ e $\Phi_{\mathrm{C}}$ para os efeitos dos tratamentos podem ser observados na Tabela 4.

Entre os tratamentos, o maior valor obtido de $\mathrm{A}_{\mathrm{P}}$ foi de 176,30 $\mathrm{cm}$ no $\mathrm{T} 1$, que diferiu significativamente daquele verificado nos demais, exceto em T2 que, por ventura, se assemelhou aos T3 e T4. Por outrolado, a menor média foi verificada em T8 cujo valor foi de $150,70 \mathrm{~cm}$, inferior em $14,52 \%$ ao ser comparado ao valor médio obtido em T1, o qual não diferiu dos valores médios mensurados em T5, T6 e T7 (Tabela 4).

Esses resultados podem ser explicados levando-se em conta que a deficiência hídrica acarretou, sem dúvida, reduções no potencial da água das células componentes do caule até o alcance de um nível de potencial hídrico inferior ao mínimo necessário para o desencadeamento do processo de alongamento celular dos entrenós acarretando, dentre as consequências, uma altura menor das plantas (Nezami et al., 2008).

Com relação aos dados de número de folhas observou-se que o déficit de irrigação no estádio vegetativo reduziu significativamente a variável morfológica em questão, de tal

Tabela 3. Resumo das análises de variância das variáveis morfológicas e de fitomassa do girassol cultivado com déficits de irrigação em seus estádios de desenvolvimento ${ }^{\#}$

\begin{tabular}{|c|c|c|c|c|c|c|c|c|c|c|}
\hline \multirow{2}{*}{ FV } & \multirow{2}{*}{ GL } & \multicolumn{9}{|c|}{ Teste F } \\
\hline & & $A_{p}$ & $\mathbf{N}_{\mathrm{F}}{ }_{\mathrm{F}}$ & $\Phi_{c}$ & $A_{F}$ & $\mathrm{MS}_{\mathrm{F}}$ & $\mathrm{MS}_{\mathrm{p}}$ & $\mathrm{MS}_{\text {CAU }}$ & $\mathbf{M S}_{\mathrm{CAP}}$ & $\mathrm{MS}_{\mathrm{T}}$ \\
\hline Blocos & 3 & 11,20 & 15,56 & 1,51 & 0,72 & 14,53 & 12,42 & 23,95 & 9,58 & 2,86 \\
\hline Trat. (T) & 7 & $21,83^{\star \star}$ & $25,76^{\star \star}$ & $71,19^{* *}$ & $95,74^{* *}$ & $61,85^{\star \star}$ & $16,61^{\star \star}$ & $36,34^{\star \star}$ & $16,04^{* *}$ & $94,38^{\star \star}$ \\
\hline Resíduo (T) & 21 & - & - & - & - & - & - & - & - & - \\
\hline Épocas (E) & 2 & $416,39^{\star \star}$ & $3067,49^{\star \star}$ & $113,83^{* \star}$ & $2449,00^{* \star}$ & $104,21^{\star \star}$ & $97,82^{\star \star}$ & $6,56^{\star \star}$ & $178,73^{\star \star}$ & $27,70^{* \star}$ \\
\hline$T \times E$ & 14 & $0,95^{\mathrm{ns}}$ & $1,10^{\text {ns }}$ & $1,72^{\mathrm{ns}}$ & $16,41^{\star \star}$ & $2,61^{\star \star}$ & $2,452^{*}$ & $2,78^{\star *}$ & $4,33^{\star \star}$ & $5,02^{\star \star}$ \\
\hline Resíduo (E) & 48 & - & - & - & - & - & - & - & - & - \\
\hline CV - T (\%) & - & 4,44 & 5,11 & 4,28 & 7,38 & 8,34 & 15,33 & 11,32 & 23,23 & 7,51 \\
\hline$C V-E(\%)$ & - & 3,54 & 6,78 & 0,74 & 6,26 & 20,35 & 25,28 & 18,76 & 34,72 & 16,21 \\
\hline
\end{tabular}

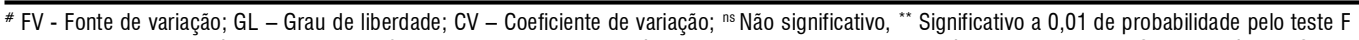

altura de plantas $\left(A_{P}\right)$, número de folhas $\left(N_{F}^{0}\right)$, diâmetro do caule $\left(\Phi_{C}\right)$, área foliar $\left(A_{F}\right)$ e de fitomassa, matéria seca da folha $\left(M_{F}\right)$, do pecíolo $\left(M_{\mathrm{P}}\right)$, do caule $\left(\mathrm{MS}_{\mathrm{CAu}}\right)$, do capítulo $\left(\mathrm{MS}_{\mathrm{CAP}}\right)$ e total $\left(\mathrm{MS}_{\mathrm{T}}\right)$ do girassol

Tabela 4. Médias das variáveis morfológicas altura de plantas - $A_{p}$, número de folhas - $\mathrm{N}_{F}^{o}$ e diâmetro do caule $-\Phi_{C}$ girassol cultivado com déficits de irrigação em seus estádios de desenvolvimento\#

\begin{tabular}{lrrrrrrrrr}
\hline Variáveis & T1 & T2 & T3 & T4 & T5 & T6 & T7 & T8 & DMS \\
$\mathrm{A}_{\mathrm{P}}(\mathrm{cm})$ & $176,30 \mathrm{a}$ & $168,60 \mathrm{ab}$ & $165,96 \mathrm{~b}$ & $164,17 \mathrm{~b}$ & $152,87 \mathrm{c}$ & $152,49 \mathrm{c}$ & $152,12 \mathrm{c}$ & $150,70 \mathrm{c}$ & 9,76 \\
$\mathrm{~N}_{\mathrm{F}}($ unidade $)$ & $23,90 \mathrm{a}$ & $23,43 \mathrm{a}$ & $22,67 \mathrm{a}$ & $22,73 \mathrm{a}$ & $20,15 \mathrm{~b}$ & $20,03 \mathrm{~b}$ & $20,51 \mathrm{~b}$ & $20,26 \mathrm{~b}$ & 1,51 \\
$\Phi_{\mathrm{C}}(\mathrm{mm})$ & $24,39 \mathrm{a}$ & $21,52 \mathrm{~b}$ & $21,12 \mathrm{~b}$ & $22,05 \mathrm{~b}$ & $19,61 \mathrm{c}$ & $19,03 \mathrm{c}$ & $18,82 \mathrm{~cd}$ & $17,78 \mathrm{~d}$ & 1,20 \\
\hline
\end{tabular}

\#Médias seguidas por letras diferentes na linha diferem estatisticamente entre si pelo teste de Tukey a 0,05 de probabilidade

T1 - tratamento em que a cultura não sofreu nenhum déficit hídrico nos três estádios fenológicos; T2 - a cultura sofreu déficit hídrico no estádio de formação da produção; T3 - déficit hídrico no estádio de floração; T4 - déficit hídrico nos estádios de floração e formação da produção; T5 - déficit hídrico no estádio vegetativo; T6 - déficit hídrico nos estádios vegetativo e formação da produção; T7 - déficit hídrico nos estádios vegetativo e floração e T8: déficit hídrico nos três estádios fenológicos 
forma que nos tratamentos cultivados com $100 \%$ da ETo durante a fase vegetativa (T1, T2, T3 e T4) foram observados os maiores números de folha, que se assemelharam entre si e foram superiores estatisticamente aos obtidos nos demais tratamentos revelando que nesta característica morfológica, em função dos valores médios de todas as épocas de avaliação, as plantas não conseguiram expressar, ao longo do ciclo, características de recuperação dos efeitos da deficiência de água na qual se encontravam expostos durante a época vegetativa, o que era esperado tendo em vista que, segundo Leite et al. (2005), na espécie o número de folhas é definido precocemente entre os dez a vinte dias após a emergência, fase na qual se procede à diferenciação celular. Dos resultados constatou-se ainda que a irrigação deficiente durante todo o ciclo (T8) reduziu em aproximadamente $16 \%$ o número médio de folhas, comparando-se com o tratamento cultivado plenamente sem déficit (T1) (Tabela 4).

Referidos resultados estão condizentes com informações de Nazarli et al. (2010) ao verificarem que, mediante a irrigação com 0,$75 ; 0,50$ e $0,25 \%$ da capacidade de campo, o déficit hídrico reduziu significativamente o número de folhas por planta no girassol. Segundo os autores, nesta espécie as folhas constituem a principal fonte de produção de fotossintatos que são essenciais para o enchimento dos aquênios e qualquer incidência de déficit hídrico independente do período de crescimento acarreta reduções no desempenho agronômico em decorrência da redução do próprio número de folhas emitidas, tal como pela perda de turgescência das folhas remanescentes.

Em contrapartida, essas observações contrariam os relatos de Göksoy et al. (2004), que avaliaram a aplicação da irrigação plena e limitada ao longo dos diferentes períodos de crescimento do girassol e averiguaram que os treze tratamentos de irrigação avaliados não foram capazes de exercer efeitos estatisticamente significativos sobre o número de folhas por planta. No entanto, os autores também corroboram com a presente pesquisa ao constatarem que a característica altura das plantas respondeu significativamente à irrigação, cuja maior altura foi observada no tratamento em que a cultura foi plenamente irrigada durante todo o ciclo.

Segundo Karadoðan \& Akgün (2009), o crescimento e o desenvolvimento das folhas exercem profundas influências no rendimento dos vegetais e desempenham papel vital no controle da perda de água pela espécie. Esses autores avaliaram os efeitos da remoção de folhas no desempenho agronômico do girassol e evidenciaram que a redução do número de folhas reduziu significativamente o rendimento e a produção de aquênios e os teores de óleo e proteína bruta no girassol. O que reforça a importância da manutenção de um número adequado de folhas como aparato fotossintético capaz de acumular, além de nutrientes, compostos orgânicos que, posteriormente, serão translocados para os órgãos reprodutivos e os aquênios (Lima Júnior et al., 2010).

Quanto ao $\Phi_{C}$, a aplicação contínua de $100 \%$ da ETo durante todo o ciclo (T1) propiciou os melhores resultados com valor médio entre as épocas de avaliação de $24,39 \mathrm{~mm}$, que diferiu estatisticamente de todos os demais tratamentos podendo-se inferir que a deficiência hídrica causa redução no crescimento e no atraso no desenvolvimento do caule. Entre T2, T3 e T4 não foram encontradas diferenças significativas na variável em questão levando-se a crer que a irrigação sem déficit durante a fase vegetativa é capaz de favorecer o diâmetro do caule porém nãoé suficiente para conferir, às plantas, o alcance de um valor máximo limitado apenas pelo potencial genético da cultivar (Tabela 4).

Por outro lado, a exposição ao déficit hídrico durante a fase vegetativa e a irrigação plena em uma ou nas duas fases remanescentes, não é suficiente para recuperar os efeitos do déficit sob a variável morfológica em questão, fato evidenciado pela inferioridade estatística dos valores médios observados em T5, T6, T7 e T8, de tal forma que se mensura, entre T1 e T8, uma divergência, em termos percentuais da ordem de $29 \%$ (Tabela 4).

Mencionados resultados são consistentes haja vista que Nezami et al. (2008) relatam que, em condições de campo, um dos efeitos da redução na disponibilidade hídrica sob a morfologia do girassol é a redução do diâmetro do caule, em função do menor crescimento do raio do caule, condições em que o crescimento da haste principal e dos ramos laterais é suprimido e, por conseguinte, é encerrada uma partição menor de matéria seca no caule. Conforme Taiz \& Zeiger (2009), é provável que o crescimento do caule seja influenciado pelos mesmos princípios que governam a restrição do crescimento das folhas, diante do déficit hídrico.

Para Biscaro et al. (2008), elevados diâmetros do caule no girassol constituem uma característica considerada desejável em virtude de conferir, à cultura, menor vulnerabilidade ao acamamento e por favorecer a execução de práticas de manejo e tratos culturais.

Entre as médias das épocas de avaliação verificou-se que o maior valor de $A_{p}(181,70 \mathrm{~cm})$ foi registrado ao término do estádio de floração $\left(68^{\circ} \mathrm{DAS}\right)$ ocorrendo diferença estatística em relação às demais de tal forma que, ao final do ciclo $\left(110^{\circ}\right.$ DAS) mensurou-se a menor das alturas, inferior em $23 \%$ quando comparada ao máximo valor (Tabela 5). Esses resultados também estão condizentes com informações de Carvalho (2004) que obteve maior altura de plantas de girassol em pleno florescimento e é superior à obtida pelo autor, que foi em média de $162 \mathrm{~cm}$.

Tabela 5. Médias das variáveis morfológicas altura de plantas - $\mathrm{A}_{\mathrm{p}}$, número de folhas - $\mathrm{N}_{\mathrm{F}^{\prime}}^{\mathrm{O}}$ e diâmetro do caule - $\Phi_{C}$ área foliar aos 52,68 e $110^{\circ}$ DAS $^{\#}$

\begin{tabular}{rccc}
\hline DAS & $\mathbf{A}_{\mathbf{P}} \mathbf{( c m )}$ & $\mathbf{N}_{\mathbf{F}}$ (unidade) & $\mathbf{\Phi}_{\mathbf{C}}(\mathbf{m m})$ \\
$52^{\circ}$ & $158,66 \mathrm{~b}$ & $29,05 \mathrm{~b}$ & $20,27 \mathrm{c}$ \\
$68^{\circ}$ & $181,70 \mathrm{a}$ & $30,99 \mathrm{a}$ & $20,50 \mathrm{~b}$ \\
$110^{\circ}$ & $140,84 \mathrm{C}$ & $5,08 \mathrm{C}$ & $20,84 \mathrm{a}$ \\
\hline DMS & 3,43 & 0,89 & 0,09 \\
\hline
\end{tabular}

\# As letras diferentes nas colunas indicam que as médias diferem estatisticamente entre si pelo teste de Tukey a 0,05 de probabilidade

De acordo com Tomich et al. (2003), a altura de plantas é uma característica importante por ser, normalmente, positivamente correlacionada com as características de produção. Segundo os autores, em ensaio conduzido em Sete Lagoas, MG, este parâmetro morfológico variou, nos treze genótipos avaliados, em média de 178 a $268 \mathrm{~cm}$ para cultivares de porte 
baixo e alto, respectivamente, sendo os valores, portanto, inferiores aos obtidos nesta pesquisa, aos 52 e $110^{\circ} \mathrm{DAS}$.

$\mathrm{O}$ maior número médio de folhas foi observado aos $68^{\circ}$ DAS $(30,99)$ superior estatisticamente ao contabilizado aos $52^{\circ}$ DAS $(29,09)$ que passou a decrescer em seguida até a senescência de tal forma que, ao final do ciclo $\left(110^{\circ} \mathrm{DAS}\right)$ se registrou o menor dos valores $(5,08)$, inferior em $84 \%$ ao ser comparado com o valor máximo (Tabela 5). Tais resultados são semelhantes aos obtidos por Amorim et al. (2007) que aferiram a diversidade genética entre 15 genótipos de girassol e verificaram que durante o florescimento os genótipos continham, em média, 29 folhas.

Tais resultados são ainda condizentes com informações de Neves et al. (2005), que mensuraram o número de folhas do girassol ornamental aos 7, 14, 21, 28, 35, 42, 49, 56, 63 e 70 dias após a emergência e constataram que houve decréscimo do número de folhas ao longo das avaliações, caracterizando a fase final da maturação com a senescência e a perda de folhas, tal como ocorreu no presente trabalho.

Para o diâmetro do caule houve diferenças estatísticas significativas entre as épocas de avaliação sinalizando que os valores foram estatisticamente crescentes com o avanço dos estádios de desenvolvimento da cultura e os valores máximos (20,84 mm) ocorreram aos $110^{\circ}$ DAS (Tabela 5). O incremento do diâmetro do caule em função dos estádios de desenvolvimento é importante no girassol e reflete os acúmulos culminantes de fitomassa seca, ao longo do ciclo no caule, no intuito de sustentar a futura produção; estima-se, então, em termos percentuais, que entre os $52^{\circ}$ DAS e os demais estádios houve incrementos de 1,12 e $2,73 \%$, entre os $68^{\circ}$ e $110^{\circ} \mathrm{DAS}$, respectivamente.

Segundo Leite et al. (2005), ao final do ciclo os girassóis devem apresentar, para serem fortes e resistentes ao acamamento, dentre suas características morfológicas, elevados diâmetros de caules a fim de sustentar a produção de capítulos com grande número de aquênios, resultados esses condizentes com informações dos referidos autores ao salientarem que os caules das cultivares de girassóis atualmente disponíveis, atingem em média de 10 a $80 \mathrm{~mm}$, sendo que os valores mensurados se situam neste intervalo.

O desdobramento em teste de médias das interações significativas para a variável morfológica $\mathrm{A}_{\mathrm{F}}$ e para as variáveis de fitomassa $\mathrm{MS}_{\mathrm{F}}, \mathrm{MS}_{\mathrm{P}} \mathrm{MS}_{\mathrm{CAU}}, \mathrm{MS}_{\mathrm{CAP}}$ e $\mathrm{MS}_{\mathrm{T}}$, pode ser observado na Tabela 6.

Estudando o efeito dos tratamentos dentro de cada época de avaliação constatou-se que, aos $52^{\circ}$ DAS, os tratamentos que não foram submetidos à deficiência hídrica durante o estádio vegetativo (T1, T2, T3 e T4), tiveram a $A_{F}$ e suas produções de $\mathrm{MS}_{\mathrm{F}}, \mathrm{MS}_{\mathrm{P}}$ e $\mathrm{MS}_{\mathrm{T}}$, favorecidas, superando estatisticamente aquelas obtidas nos demais (Tabela 6).

$\mathrm{O}$ comportamento da $\mathrm{A}_{\mathrm{F}}$ frente aos déficits de irrigação impostos, pode ser explicado levando-se em conta as informações de Taiz \& Zeiger (2009), que reportam o processo de expansão foliar do girassol como dependente do estado de turgidez celular.

Tabela 6. Médias de área foliar $-\mathrm{A}_{\mathrm{F}}\left(\mathrm{cm}^{2}\right.$ planta $\left.{ }^{-1}\right)$, fitomassa seca da folha $-\mathrm{MS}_{\mathrm{F}}$, do pecíolo $-\mathrm{MS}_{\mathrm{P}}$, do $\mathrm{caule}-\mathrm{MS}_{\mathrm{CAU}}$ do capítulo - $\mathrm{MS}_{\mathrm{CAP}}$ e total da parte aérea $-\mathrm{MS}_{\mathrm{T}}\left(\mathrm{g}_{\mathrm{g}}\right.$ planta-1$\left.^{-1}\right)$ do girassol cultivado com déficits de irrigação em seus estádios de desenvolvimento aos $52^{\circ}, 68^{\circ}$ e $110^{\circ}$ dia após a semeadura (DAS) ${ }^{\#}$

\begin{tabular}{|c|c|c|c|c|c|c|c|c|}
\hline DAS & $\mathrm{T} 1$ & T2 & T3 & $\mathrm{T} 4$ & T5 & T6 & $\mathrm{T} 7$ & T8 \\
\hline $\begin{array}{c}52^{\circ} \\
68^{\circ} \\
110^{\circ}\end{array}$ & $\begin{array}{l}73121,65 \mathrm{aA} \\
63491,64 \mathrm{aB} \\
21806,98 \mathrm{aC}\end{array}$ & $\begin{array}{c}68804,98 \mathrm{aA} \\
64198,33 \mathrm{aB} \\
18913,93 \mathrm{abC}\end{array}$ & $\begin{array}{c}68475,24 \mathrm{aA} \\
66543,77 \mathrm{aA} \\
17508,10 \mathrm{abcB}\end{array}$ & $\begin{array}{c}A_{F}\left(\mathrm{~cm}^{2} p\right. \\
70006,2 \mathrm{aA} \\
60685,5 \mathrm{aB} \\
16320,75 \mathrm{abcC}\end{array}$ & $\begin{array}{l}\left.\text { nta }^{-1}\right) \\
45512,86 \text { bA } \\
43743,97 \text { bA } \\
15143,79 \text { bcB }\end{array}$ & $\begin{array}{c}45264,4 \mathrm{bA} \\
46724,7 \mathrm{bA} \\
12841,58 \mathrm{bcB}\end{array}$ & $\begin{array}{l}45386,55 \mathrm{bA} \\
41737,95 \mathrm{bA} \\
11900,60 \mathrm{cB}\end{array}$ & $\begin{array}{l}46721,74 \mathrm{bA} \\
45878,98 \mathrm{bA} \\
11240,92 \mathrm{cB}\end{array}$ \\
\hline $\begin{array}{c}52^{\circ} \\
68^{\circ} \\
110^{\circ} \\
\end{array}$ & $\begin{array}{l}40,08 \mathrm{aA} \\
27,98 \mathrm{aB} \\
18,23 \mathrm{aC}\end{array}$ & $\begin{array}{l}41,46 \mathrm{aA} \\
28,81 \mathrm{aB} \\
18,48 \mathrm{aB}\end{array}$ & $\begin{array}{l}41,93 \mathrm{aA} \\
26,25 \mathrm{aB} \\
18,06 \mathrm{aB}\end{array}$ & $\begin{array}{l}\mathrm{MS}_{\mathrm{F}}(\mathrm{g} \mathrm{p} \\
40,90 \mathrm{aA} \\
27,39 \mathrm{aB} \\
12,17 \mathrm{aC}\end{array}$ & $\begin{array}{r}\left(\mathrm{nt}^{-1}\right) \\
25,84 \mathrm{bA} \\
22,33 \mathrm{aA} \\
18,25 \mathrm{aA} \\
\end{array}$ & $\begin{array}{l}24,86 \mathrm{bA} \\
21,47 \mathrm{aA} \\
12,14 \mathrm{aB}\end{array}$ & $\begin{array}{l}24,99 \mathrm{bA} \\
21,68 \mathrm{aA} \\
12,24 \mathrm{aB}\end{array}$ & $\begin{array}{l}24,23 \mathrm{bA} \\
21,82 \mathrm{aA} \\
11,91 \mathrm{aB}\end{array}$ \\
\hline $\begin{array}{r}52^{\circ} \\
68^{\circ} \\
110^{\circ} \\
\end{array}$ & $\begin{array}{r}21,72 \mathrm{aA} \\
12,11 \mathrm{aB} \\
7,99 \mathrm{aB} \\
\end{array}$ & $\begin{array}{r}21,04 \mathrm{aA} \\
11,75 \mathrm{aB} \\
8,16 \mathrm{aB} \\
\end{array}$ & $\begin{array}{r}20,67 \mathrm{aA} \\
12,35 \mathrm{aB} \\
8,19 \mathrm{aB} \\
\end{array}$ & $\begin{array}{c}\mathrm{MS}_{\mathrm{P}} \text { (g plant } \\
22,14 \mathrm{aA} \\
12,01 \mathrm{aB} \\
5,54 \mathrm{aC}\end{array}$ & $\begin{array}{r}12,24 \mathrm{bA} \\
10,03 \mathrm{aA} \\
8,10 \mathrm{aA}\end{array}$ & $\begin{array}{c}12,91 \mathrm{bA} \\
10,18 \mathrm{aAB} \\
5,68 \mathrm{aB} \\
\end{array}$ & $\begin{array}{c}12,63 \mathrm{bA} \\
10,01 \mathrm{aAB} \\
5,65 \mathrm{aB} \\
\end{array}$ & $\begin{array}{c}13,73 \mathrm{bA} \\
10,00 \mathrm{aAB} \\
5,59 \mathrm{aB} \\
\end{array}$ \\
\hline $\begin{array}{r}52^{\circ} \\
68^{\circ} \\
110^{\circ} \\
\end{array}$ & $\begin{array}{l}62,99 \mathrm{aA} \\
66,92 \mathrm{abA} \\
66,20 \mathrm{aA} \\
\end{array}$ & $\begin{array}{l}59,33 \mathrm{abA} \\
73,07 \mathrm{aA} \\
67,53 \mathrm{aA} \\
\end{array}$ & $\begin{array}{l}58,92 \text { abA } \\
74,94 \text { aA } \\
67,39 \text { aA } \\
\end{array}$ & $\begin{array}{l}\mathrm{MS}_{\mathrm{CAU}} \text { (g plant } \\
60,41 \mathrm{abA} \\
71,64 \mathrm{aA} \\
37,00 \mathrm{bB} \\
\end{array}$ & 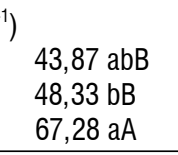 & $\begin{array}{l}43,79 \mathrm{abA} \\
48,78 \mathrm{bA} \\
38,68 \mathrm{bA} \\
\end{array}$ & $\begin{array}{l}42,45 \mathrm{bA} \\
49,20 \mathrm{bA} \\
35,43 \mathrm{bA}\end{array}$ & $\begin{array}{l}44,67 \mathrm{abA} \\
48,23 \mathrm{bA} \\
37,26 \mathrm{bA} \\
\end{array}$ \\
\hline $\begin{array}{c}52^{\circ} \\
68^{\circ} \\
110^{\circ}\end{array}$ & $\begin{array}{l}12,60 \mathrm{aC} \\
44,93 \mathrm{aB} \\
95,85 \mathrm{aA}\end{array}$ & $\begin{array}{r}10,59 \mathrm{aC} \\
43,46 \mathrm{aB} \\
108,53 \mathrm{aA}\end{array}$ & $\begin{array}{r}9,71 \mathrm{aC} \\
46,96 \mathrm{aB} \\
103,13 \mathrm{aA}\end{array}$ & $\begin{array}{l}\mathrm{MS}_{\text {CAP }} \text { (g plant } \\
10,73 \mathrm{aB} \\
46,48 \mathrm{aA} \\
50,70 \mathrm{bA}\end{array}$ & $\begin{array}{r}6,92 \mathrm{aC} \\
32,44 \mathrm{aB} \\
99,35 \mathrm{aA}\end{array}$ & $\begin{array}{r}5,79 \text { aB } \\
32,17 \text { aA } \\
49,26 \text { bA }\end{array}$ & $\begin{array}{r}5,94 \mathrm{aB} \\
32,94 \mathrm{aA} \\
52,40 \mathrm{bA}\end{array}$ & $\begin{array}{r}6,37 \mathrm{aB} \\
32,58 \mathrm{aA} \\
50,28 \mathrm{bA}\end{array}$ \\
\hline $\begin{array}{c}52^{\circ} \\
68^{\circ} \\
110^{\circ}\end{array}$ & $\begin{array}{l}137,38 \mathrm{aB} \\
151,94 \mathrm{abAB} \\
188,27 \mathrm{aA}\end{array}$ & $\begin{array}{l}132,42 a B \\
157,09 a B \\
202,70 a A\end{array}$ & $\begin{array}{l}131,23 \mathrm{aB} \\
160,50 \mathrm{aAB} \\
196,77 \mathrm{aA}\end{array}$ & $\begin{array}{l}\mathrm{MS}_{\mathrm{T}} \text { (g planta } \\
134,18 \mathrm{aAB} \\
157,51 \mathrm{aA} \\
105,40 \mathrm{bB}\end{array}$ & $\begin{array}{r}88,86 \mathrm{bB} \\
113,12 \mathrm{bB} \\
192,98 \mathrm{aA}\end{array}$ & $\begin{array}{r}87,34 \text { bA } \\
112,60 \mathrm{bA} \\
105,76 \mathrm{bA}\end{array}$ & $\begin{array}{r}86,00 \text { bA } \\
113,82 \text { bA } \\
105,72 \text { bA }\end{array}$ & $\begin{array}{r}89,00 \text { bA } \\
112,63 \text { bA } \\
105,04 \text { bA }\end{array}$ \\
\hline
\end{tabular}

\#Médias seguidas de letras iguais maiúsculas nas colunas e minúsculas nas linhas não diferem estatisticamente entre si pelo teste de Tukey a $5 \%$ de probabilidade, $A_{\mathrm{F}}\left(\mathrm{DMS}_{\mathrm{L}}=6277,85 ; \mathrm{DMS}_{\mathrm{C}}=4564,05\right)$ $\mathrm{MS}_{\text {FO HA }}\left(\mathrm{DMS}_{\mathrm{L}}=9,36 ; \mathrm{DMS}_{\mathrm{C}}=8,46\right) ; \mathrm{MS}_{\mathrm{p}}\left(\mathrm{DMS}_{\mathrm{L}}=5,82 ; \mathrm{DMS}_{\mathrm{C}}=5,05\right) ; \mathrm{MS}_{\mathrm{CAU}}\left(\mathrm{DMS}_{\mathrm{L}}=20,22 ; \mathrm{DMS}_{\mathrm{C}}=17,57\right) ; \mathrm{MS}_{\mathrm{CAP}}\left(\mathrm{DMS}_{1}=28,65 ; \mathrm{DMS}_{\mathrm{C}}=24,49\right) ; \mathrm{MS}_{\mathrm{T}}\left(\mathrm{DMS}_{\mathrm{L}}=40,91 ; \mathrm{DMS}_{\mathrm{C}}=36,36\right)$

T1 - tratamento em que a cultura não sofreu nenhum déficit hídrico nos três estádios fenológicos; T2 - a cultura sofreu déficit hídrico no estádio de formação da produção; T3 - déficit hídrico no estádio de floração; T4 - déficit hídrico nos estádios de floração e formação da produção; T5 - déficit hídrico no estádio vegetativo; T6 - déficit hídrico nos estádios vegetativo e formação da produção; T7 - déficit hídrico nos estádios vegetativo e floração e T8: déficit hídrico nos três estádios fenológicos 
Os autores também informam que a taxa fotossintética da folha do girassol tipicamente não é tão responsiva aos efeitos do déficit hídrico quanto à área foliar, a tal ponto que a expansão foliar na espécie chega a ser completamente inibida sob níveis moderados de estresse por escassez de água.

Os resultados de $\mathrm{MS}_{\mathrm{F}}, \mathrm{MS}_{\mathrm{P}}, \mathrm{MS}_{\mathrm{CAU}}, \mathrm{MS}_{\mathrm{CAP}}$ e $\mathrm{MS}_{\mathrm{T}}$ estão condizentes com informações de Santos et al. (2002) ao reportarem respostas diferenciadas sobre a acumulação de fitomassa no girassol em decorrência da variabilidade temporal da precipitação pluvial acumulada durante a estação de cultivo. Segundo esses autores, tal comportamento é justificado pelo fato da distribuição da precipitação ter ocorrido de forma irregular durante os distintos estádios de desenvolvimento da cultura, em detrimento da própria quantidade total de precipitação pluvial incidente durante o ciclo; portanto, este fato evidencia que os estádios fenológicos do girassol se distinguem quanto ao dispêndio de água revelando, assim, a importância do suprimento hídrico adequado durante a fase vegetativa para a efetivação de um vigoroso crescimento por parte das plantas, refletido em elevadas produções de fitomassa.

Andrade \& Abreu (2007) informam que a produção de matéria seca no girassol sob déficit hídrico é negativamente afetada devido, sem dúvida, à redução da área foliar e consequente redução da radiação solar interceptada e utilizada na produção de biomassa.

Com relação à $\mathrm{MS}_{\mathrm{CAU}}$, até o presente estádio apenas os tratamentos T1 e T7 diferiram estatisticamente entre si, porém sem denotação de diferenças estatisticamente significativas com relação aos demais. Ainda para esta mesma época de avaliação a $\mathrm{MS}_{\mathrm{CAP}}$ não diferiu estatisticamente entre os tratamentos (Tabela 6) comportamento já esperado visto que, aos $52^{\circ}$ DAS, a cultura se enquadrava no estádio R4 (floração inicial) e até então, conforme Gomes et al. (2010) o processo de redistribuição de assimilados da fitomassa (fonte) para a produção de aquênios (dreno) não tinha, de fato, se iniciado (Tabela 6).

Para Zobiole et al. (2010), ao longo dos diferentes estádios de desenvolvimento do girassol a ocasião de maior assimilação de nutrientes e acumulação de matéria seca se sucede no começo do florescimento até a fase de maturação fisiológica dos aquênios, quando o ponto de máxima é então alcançado.

Aos $68^{\circ}$ DAS apenas as variáveis $A_{F}, M_{C A U}$ e $M_{T}$ apresentaram diferenças significativas entre os tratamentos (Tabela 6). De forma semelhante, nessas variáveis os tratamentos submetidos à deficiência hídrica no estádio vegetativo também registraram os menores valores e diferiram estatisticamente dos cultivados sem déficit durante este mesmo estádio (Tabela 6). Referidos resultados também são condizentes com informações de Nobre et al. (2010), ao relatarem que a produção de matéria seca está fortemente associada à lâmina de irrigação disponibilizada à cultura; ainda segundo esses autores, na medida em que se incrementou a reposição da necessidade hídrica na cultura do girassol foram constatados acréscimos na produção de fitomassa total da parte aérea cujos maiores incrementos foram observados com a reposição de $120 \%$ da necessidade hídrica da cultura, mediante balanço hídrico.
Ainda para esta época de avaliação, nos tratamentos T3 e T4 o déficit hídrico imposto até então apenas durante o estádio de floração, não foi capaz de denotar diferenças estatisticamente significativas na $\mathrm{A}_{\mathrm{F}}$ e na $\mathrm{MS}_{\mathrm{CAU}}$, quando comparadas com as demais (Tabela 6). Este comportamento era previsto de vez que a exposição ao déficit hídrico até decorrido o estádio por apenas 16 dias, não foi capaz de afetar o fluxo de fitomassa pela espécie, a este respeito Marques et al. (2009) salientam que os efeitos da deficiência hídrica sobre os vegetais variam com o tipo, a intensidade e a duração do estresse.

Quanto à $\mathrm{MS}_{\mathrm{T}}$, os tratamentos T2, T3 e T4 não diferiram entre si e apresentaram os maiores valores quando comparados aos tratamentos T5, T6, T7 e T8, que do mesmo modo não diferiram estatisticamente entre si (Tabela 6).

Com relação à avaliação realizada aos $110^{\circ} \mathrm{DAS}$ presume-se que na $A_{F}$ foram evidenciadas diferenças entre os tratamentos, de tal forma que os tratamentos T7 e T8 se assemelharam entre si e denotaram os menores valores com relação aos demais; no entanto, em T5 e T6, embora cultivados sob estresse durante a fase vegetativa conseguiram, ao final do ciclo, recuperar a área foliar no mesmo nível dos tratamentos T3 e T4; apesar disto, apenas T1 e T2 diferiram totalmente dos demais e o T2 se assemelhou estatisticamente ao T1 que, por sua vez, também não diferiu de T2, T3 nem de T4.

Ainda nesta mesma época de avaliação se observou que os déficits de irrigação aplicados ao longo do ciclo da cultura não interferiram significativamente nas variáveis $\mathrm{MS}_{\mathrm{F}}$ e $\mathrm{MS}_{\mathrm{P}}$ do girassol. Quanto às demais variáveis $\left(\mathrm{MS}_{\mathrm{CAU}}, \mathrm{MS}_{\mathrm{CAP}}\right.$ e $\left.\mathrm{MS}_{\mathrm{T}}\right)$, constatou-se comportamento semelhante, de tal forma que os tratamentos T1, T2, T3 e T5 superaram estatisticamente aqueles observados nos demais tratamentos que, por ventura, não difeririam significativamente quando comparados entre si (Tabela 6).

Uma observação importante é que a fitomassa total final (110 $\left.{ }^{\circ} \mathrm{DAS}\right)$ em T1 (sem déficit durante todo o ciclo) não superou estatisticamente todos os tratamentos. Cumpre salientar que o tratamento T5, embora tenha sido exposto ao déficit hídrico durante o estádio vegetativo conseguiu, ao final do ciclo, recuperar sua fitomassa nas variáveis $\mathrm{MS}_{\mathrm{CAU}}, \mathrm{MS}_{\mathrm{CAP}}$ e $\mathrm{MS}_{\mathrm{T}}$, a um nível comparado estatisticamente a T1, de maneira que o mesmo não mais apresentou, na presente avaliação sensibilidade a nível de déficit hídrico imposto, mantendo a assimilação orgânica e alcançando valores que não diferiram estatisticamente dos tratamentos plenamente irrigados durante o estádio em questão (Tabela 6) o que reforça a hipótese de que, em alguns estádios de desenvolvimento, as lâminas de irrigação podem ser reduzidas sem ocasionar decréscimos significativos na produtividade e discordam dos resultados obtidos por Castro et al. (2006), ao concluírem que a produção de fitomassa seca do girassol apresentou o mesmo comportamento, independente das fases de exposição da cultura ao estresse hídrico em que as maiores produções foram obtidas nos tratamentos submetidos à maior disponibilidade de água, e dos relatos de Göksoy et al. (2004), ao discorrerem que o máximo acúmulo de matéria seca foi observado quando as irrigações foram aplicadas em sua totalidade, ao longo do ciclo. 
Por outro lado, o tratamento T4, embora irrigado com $100 \%$ da ETo durante a fase vegetativa teve, ao final do ciclo, sua $\mathrm{MS}_{\mathrm{T}}$ estatisticamente equiparada ao tratamento cultivado com irrigação deficitária, em todo o ciclo (T8), mostrando ser a cultura, nos estádios de floração e formação da produção, bastante sensível ao déficit hídrico e à essencialidade do suprimento hídrico adequado, durante as fases críticas da cultura floração e formação da produção, conforme discorreram Leite et al. (2005) ao abordarem que a exigência em água pela cultura se vai elevando proporcionalmente ao seu crescimento, de forma que entre a formação das flores nos capítulos e o amadurecimento dos aquênios e, por conseguinte, a formação do óleo, a água é fator decisivo para se obter rendimentos consideráveis (Tabela 6).

Quanto aos efeitos das épocas de avaliação dentro de cada tratamento, ao que se relaciona a $A_{\mathrm{F}}$ ficou patente que entre $\mathrm{T} 1, \mathrm{~T} 2$ e T4 o comportamento foi semelhante de tal forma que os valores médios decresceram significativamente com o avanço dos estádios de desenvolvimento, ressaltando que o maior dos valores foi obtido aos $52^{\circ}$ DAS seguido dos 68 e $110^{\circ}$ DAS, com denotação de diferenças estatísticas quando equiparados entre si. Condutas distintas foram detectadas entre T3, T5, T6, T7 e T8 em que os valores mensurados aos 52 e $68^{\circ}$ DAS não diferiram estatisticamente entre si porém são superiores estatisticamente apenas aqueles mensurados ao final do ciclo ( $\left.110^{\circ} \mathrm{DAS}\right)$. Zobiole et al. (2010) constataram que o máximo de área foliar $\left(8.000 \mathrm{~cm}^{2}\right)$ do girassol híbrido BRS 191 cultivado no estado do Paraná, ocorreu aos $68^{\circ}$ dia após a emergência, valor inferior aos encontrados na referida pesquisa. Tais resultados ainda corroboram com informações de Neves et al. (2005) quando reportam que no girassol a variável área foliar se relaciona diretamente com o número de folhas uma vez que um maior número de folhas acarreta, evidentemente, maior área foliar.

A variável $\mathrm{MS}_{\mathrm{F}}$ exibiu comportamento estatisticamente semelhante nos tratamentos $\mathrm{T} 1 \mathrm{e} \mathrm{T} 4$, de tal forma que a mesma decresceu com o avanço dos estádios de desenvolvimento da cultura. Da forma idêntica, nos tratamentos T2 e T3 apenas foram detectadas diferenças aos $52^{\circ} \mathrm{DAS}$, quando equiparadas às demais; contrariamente foi detectada, nos tratamentos T6, T7 e T8, inferioridade estatística apenas aos $110^{\circ}$ DAS; já o T5 não foi influenciado pelas épocas de avaliação (Tabela 6).

A $\mathrm{MS}_{\mathrm{P}}$ contrariamente a $\mathrm{MS}_{\mathrm{F}}$ no $\mathrm{T} 1$ apenas diferiu estatisticamente aos $52^{\circ} \mathrm{DAS}$ com relação às demais épocas e nos tratamentos T6, T7 e T8 foi detectada superioridade estatística apenas aos $52^{\circ}$ DAS enquanto para os demais se constatou comportamento análogo ao da $\mathrm{MS}_{\mathrm{F}}$ (Tabela 6).

Ao analisar a $\mathrm{MS}_{\mathrm{CAU}}$, observa-se que em T4 as avaliações procedidas aos 52 e $68^{\circ}$ DAS não difeririam entre si, mas superam estatisticamente aquela realizada ao final do ciclo $\left(110^{\circ} \mathrm{DAS}\right)$. Inversamente, em T5 apenas a coleta decorrida aos $110^{\circ}$ ultrapassa estatisticamente as demais épocas; quanto aos outros tratamentos, não se detectaram diferenças com relação aos efeitos dos distintos estádios de desenvolvimento da cultura (Tabela 6).

Ao que se relaciona à $\mathrm{MS}_{\mathrm{CAP}}$, infere-se que os tratamentos T1, T2, T3 e T5 exibiram desempenhos estatisticamente similares ao longo do ciclo cultural, de tal forma que foi constatada superioridade estatística entre as épocas de avaliação com incrementos significativos desta variável com os estádios fenológicos, conforme a sequência $110^{\circ}>68^{\circ}>52^{\circ}$ DAS. Semelhantemente, em T4, T7 e T8 também foram constatados comportamentos semelhantes estatisticamente, porém com valores estatisticamente inferiores apenas ao término do estádio vegetativo (Tabela 6).

Em se tratando da $\mathrm{MS}_{\mathrm{T}}$ presume-se, pelos resultados, que em T1 e T3 se detectou superioridade estatística da avaliação procedida aos $110^{\circ}$ DAS, em relação aos resultados da avaliação aos $52^{\circ}$ DAS; mesmo assim aos $68^{\circ}$ DAS nesses mesmos tratamentos o valor se assemelhou estatisticamente aos demais enquanto nos tratamentos T2 e T5 apenas o valor mensurado aos $110^{\circ}$ DAS superou estatisticamente os demais; por outro lado, entre T6, T7 e T8 não foram evidenciadas diferenças estatísticas ao longo dos diferentes estádios de desenvolvimento da cultura (Tabela 6).

Tais resultados corroboram com Tomich et al. (2003) ao mencionarem que a produção de matéria seca dos componentes morfológicos está condicionada, dentre outros fatores, ao estádio de desenvolvimento da planta.

Os valores médios da contribuição relativa percentual da fitomassa seca da folha, do pecíolo, do caule e do capítulo na produção de fitomassa seca total do girassol nos diferentes tratamentos estudados, podem ser observados na Figura 1.

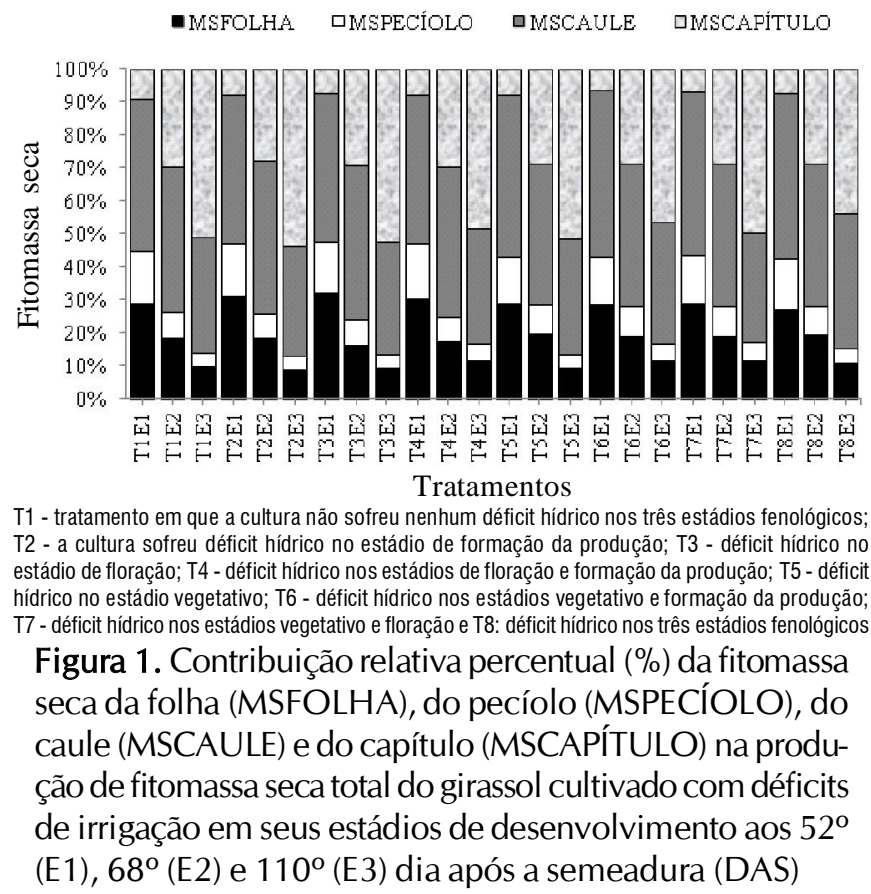

Pelos resultados verificou-se que, independente dos tratamentos, ao término de cada estádio fenológico os padrões de distribuição de massa seca entre os distintos órgãos da parte aérea da planta permaneceram praticamente semelhantes; por outro lado, a partição de fitomassa se alterou pronunciadamente ao longo das épocas de avaliação (Figura 1).

Aos $52^{\circ}$ DAS (E1) constatou-se que os caules e as folhas foram os órgãos que mais contribuíram para o acúmulo da matéria seca total, independente do tratamento (Figura 1). Tais 
observações estão condizentes com os resultados obtidos por Zobiole et al. (2010) ao relatarem que nos girassóis a produção de matéria seca tem a seguinte sequência: caule > folha > aquênio > capítulo > pecíolo.

Observam-se, aos $68^{\circ}$ DAS, incrementos na produção de fitomassa seca dos capítulos seguidos da tendência de redução da fitomassa seca das folhas enquanto a fitomassa seca do caule se manteve praticamente inalterada (Figura 1). De acordo com Paranhos et al. (1995) espera-se, durante os estádios iniciais do desenvolvimento, que a planta empregue a maior fração de sua energia total disponível na formação dos órgãos que são capazes de deter a radiação solar uma vez que o processo fotossintético é o mecanismo fisiológico no qual os processos vitais dos vegetais são assegurados.

Neste estudo grande parte do material assimilado até os $68^{\circ}$ DAS se encontrava, no entanto, encerrado nos tecidos que compõem os caules sendo que a partir de então se observa, mediante a contribuição percentual de fitomassa seca dos demais órgãos, que parte desses carboidratos produzidos passou a ser translocada, então, para os capítulos (Figura 1).

Aos $110^{\circ}$ DAS a fitomassa seca das folhas e dos pecíolos diminuiu enquanto a fitomassa seca do capítulo cresceu de forma bastante acentuada em decorrência da concretização dos processos fisiológicos de enchimento e maturação dos aquênios (Figura 1); esses resultados são condizentes com os relatos de Bruginski \& Pissaia (2002) ao também verificaram grande alteração na partição de massa seca em plantas de girassol entre os estádios florescimento e formação da produção constatando que a porcentagem de massa seca de folha, de caule e do pecíolo, diminuiu enquanto a do capítulo foi incrementada, comportamento que pode ser explicado levandose em conta as informações fornecidas por Zobiole et al. (2010) ao relatarem que o enchimento dos aquênios se consolida a partir das reservas que são acumuladas nos diferentes órgãos vegetais, destacando-se as folhas, os pecíolos e o caule, como as principais fontes de fotoassimilados para os capítulos e, por conseguinte, para os aquênios.

\section{CONClusÕES}

1. A altura da planta, o número de folhas e o diâmetro do caule, são afetados negativamente pelos efeitos isolados dos déficits de irrigação e das épocas de avaliação.

2. Os déficits de irrigação e as épocas de avaliação interagem e afetam as variáveis área foliar, massa seca da folha, do pecíolo, do caule, do capítulo e total do girassol.

3. O maior rendimento, em termos de características morfológicas e de produção de fitomassa, é obtido a partir do tratamento cultivado sem déficit de irrigação.

4. O déficit de irrigação inicializado na fase vegetativa, acarreta maior redução no crescimento e na produção de fitomassa do girassol porém, quando aplicado apenas durante esta fase, a fitomassa do caule, do capítulo e o total, conseguem se equiparar ao cultivo sem déficit de irrigação, durante o ciclo.

5. O nível de irrigação equivalente a $50 \%$ da ETo compromete a morfologia e a produção de fitomassa, quando aplicado em qualquer estádio de desenvolvimento.

\section{LITERATURA CITADA}

Amorim, E. P.; Ramos, N. P.; Ungaro, M. R. G.; Kiihl, Tammy A. M. Divergência genética em genótipos de girassol. Revista Ciência Agrotécnica, v.31, p.1637-1644, 2007.

Andrade, J. A.; Abreu, F. G. Influência da temperatura e do teor de umidade do solo na área foliar e acumulação de matéria seca durante o estabelecimento da ervilha, do milho e do girassol. Revista de Ciências Agrárias, v.30, p.27-37, 2007.

Aquino, A. B.; Aquino, B. F.; Hernandez, F. F. F.; Holanda, F. J. M.; Freire, J. M.; Crisostomo, L. A.; Costa, R. I.; Uchôa, S. C. P.; Fernandes, V. L. B. Recomendações de adubação e calagem para o Estado do CE. 1.ed. Fortaleza: UFC, 1993. $247 \mathrm{p}$.

Biscaro, G. A.; Machado, J. R.; Tosta, M. da S.; Mendonça, V.; Soratto, R. P.; Carvalho, L. A. de. Adubação nitrogenada em cobertura no girassol irrigado nas condições de CassilândiaMS. Revista Ciência e Agrotecnologia, v.32, p.1366-1373, 2008.

Bruginski, D. H.; Pissaia, A. Cobertura nitrogenada em girassol sob plantio direto na palha: II - Morfologia da planta e partição de massa seca. Revista Scientia Agraria, v.3, p.4753, 2002.

Carvalho, D. B. de. Análise de crescimento de girassol em sistema de semeadura direta. Revista Acadêmica: ciências agrárias e ambientais, v.2, p.63-70, 2004.

Castro, C. de; Moreira, A.; Oliveira, R. F. de; Dechen, A. R. Boro e estresse hídrico na produção do girassol. Revista Ciência e Agrotecnologia, v.30, p.214-220, 2006.

Fagundes, J. D.; Santiago, G.; Mello, A. M. de; Bellé, R. A.; Streck, N. A. Crescimento, desenvolvimento e retardamento da senescência foliar em girassol de vaso (Helianthus annuus L.): Fontes e doses de nitrogênio. Revista Ciência Rural, v.37, p.987-993, 2007.

Fereres, E.; Soriano, M. A. Deficit irrigation for reducing agricultural wateruse. Journal Experimental Botany, v.58, p.147-159, 2007.

Gomes, E. P.; Ávila, M. R.; Rickli, M. E.; Petri, F. Desenvolvimento e produtividade do girassol sob lâmina de irrigação em semeadura direta na região do Arenito Caiuá, estado do Paraná. Revista Irriga, v.15, p.373-385, 2010.

Göksoy, A. T.; Demir, A. O.; Turan, Z. M.; Daðüstü, N. Responses of sunflower (Helianthus annuus L.) to full and limited irrigation at different growth stages. Field Crops Research, v.87, p.167-178, 2004.

Grieu, P.; Maury, P.; Debaeke, P.; Sarrafi, A. Améliorer la tolérance à la sécheresse du tournesol: Apports del'écophysiologie et de la génétique. Revue Innovations Agronomiques, v.2, p.37-51, 2008.

Karadoðan, T.; Akgün, Í. Effect of leaf removal on sunflower yield and yield components and some quality characters. Helia, v.32, p.123-134, 2009.

Leite, R. M. V. B. C.; Brighenti, A. M.; Castro, C. de. (ed.). Girassol no Brasil. Londrina: Embrapa Soja, 2005. 613p.

Lima Júnior, I. dos S. de; Bertoncello, T. F.; Melo, E. P. de; Degrande, P. E.; Kodama, C. Desfolha artificial simulando danos de pragas na cultura do girassol (Helianthus annuus L., Asteraceae). Revista Ceres, v.57, p.23-27, 2010. 
Maldaner, I. C.; Heldwein, A. B.; Loose, L. H.; Lucas, D. D. P.; Guse, F. I.; Bortoluzzi, M. P. Modelos de determinação nãodestrutiva da área foliar em girassol. Revista Ciência Rural, v.39, p.1356-1361, 2009.

Marques, P. A. A.; Bernardi Filho, L.; Santos, A. C. P. Crescimento, produção de óleo essencial e trocas gasosas em orégano influenciados por diferentes lâminas de irrigação. Revista Ciência Rural, v.39, p.1888-1892, 2009.

Mizubuti, I. Y.; Ribeiro, E. L. de A.; Rocha, M. A. da; Silva, L. das D. F. da; Pinto, A. P.; Fernandes, W. C.; Rolim, M. A. Consumo e digestibilidade aparente das silagens de milho (Zea mays L.), sorgo (Sorghum bicolor L.) Moench) e girassol (Helianthus annuus L.). Revista Brasileira de Zootecnia, v.31, p.267-272, 2002.

Nazarli, H.; Zardashti, M. R.; Darvishzadeh, R.; Najafi, S. The effect of water stress and polymer on water use efficiency, yield and several morphological traits of sunflower under greenhouse condition. Notulae Scientia Biologicae, v.2, p.53$58,2010$.

Neves, M. B.; Buzetti, S.; Castilho, R. M. M. de; Boaro, C. S. F. Desenvolvimento de plantas de girassol ornamental (Helianthus annuus L.) em vasos, em dois substratos com solução nutritiva eem solo. Revista Científica, v.33, p.127-133, 2005.

Nezami, A.; Khazaei, H. R.; Rezazadeh, Z. B.; Hosseini, A. Effects of drought stress and defoliation on sunflower (Helianthus annuus) in controlled conditions. Journal Desert, v.12, p.99104, 2008.

Nobre, R. G.; Gheyi, H. R.; Soares, F. A. L.; Andrade, L. O. de; Nascimento, E. C. S. Produção do girassol sob diferentes lâminas com efluentes domésticos e adubação orgânica. Revista Brasileira de Engenharia Agrícola e Ambiental, v.14, p.747-754, 2010.
Oliveira, M. C.; Martins, F. F.; Almeida, C. V.; Moura, C. D. Efeito da inclusão de bagaço de girassol na ração sobre o desempenho e rendimento de carcaça de frangos de corte. Revista Portuguesa Zootecnia, v.10, p.107-116, 2003.

Paranhos, J. T.; Marchezan, E.; Dutra, L. M. C. Acúmulo de massa seca em três cultivares de arroz irrigado com diferentes arquiteturas de plantas. Revista Ciência Rural, v.25, p.55-60, 1995.

Santos, A. C. dos; Andrade, A. P. de; Lima, J. R. de S.; Silva, I. de F. da; Cavalcante, V. R. Variabilidade temporal da precipitação pluvial: Nível de nitrogênio no solo e produtividade de cultivares de girassol. Revista Ciência Rural, v.32, p.757-764, 2002.

Santos Júnior, J. A.; Gheyi, H. R.; Guedes Filho, D. H.; Dias, N. da S.; Soares, F. A. L. Cultivo de girassol em sistema hidropônico sob diferentes níveis de salinidade. Revista Ciência Agronômica, v.42, p.842-849, 2011.

Taiz, L.; Zeiger, E. Fisiologia vegetal. 4.ed. Porto Alegre: Artmed, 2009. 819p.

Tomich, T. R.; Rodrigues, J. A. S.; Gonçalves, L. C.; Tomich, R. G. P. Carvalho, A. U. Potencial forrageiro de cultivares de girassol produzidos na safrinha para ensilagem. Arquivo Brasileiro de Medicina Veterinária e Zootecnia, v.55, p.756762, 2003.

Toureiro, C. M.; Serralheiro, R. P.; Oliveira, M. R. Resposta das culturas do girassol e do milho a diferentes cenários de rega deficitária. Revista de Ciências Agrárias, v.30, p.33-47, 2007.

Zobiole, L. H. S.; Castro, C. de; Oliveira, F. A. de; Oliveira Júnior, A. de; Moreira, A. Curva de crescimento, estado nutricional, teor de óleo e produtividade do girassol híbrido BRS 191 cultivado no estado do Paraná. Revista Brasileira de Oleaginosas e Fibrosas, v.14, p.55-62, 2010. 